\title{
Analysis of Supply Terminal Layout in Sight of Economic Geography
}

\author{
Yanbo Cui ${ }^{1,}$, , Lei Shi ${ }^{1}$, and Qilong Huang ${ }^{1,2}$ \\ ${ }^{1}$ China Academy of Transportation Science, Beijing 100029, China; \\ ${ }^{2}$ School of Economics and Management, Beijing JiaoTong University, Beijing 100044, China. \\ a1669717308@qq.com
}

\begin{abstract}
This template selects the data of MI Company in 2017 to analyses the relation between distribution data of the off-line stores and the status quo of the provincial economic and social development in the same term, including the official GDP, population and income statistics. From the perspective of the layout of enterprise management, it compares the economic development difference between provinces and the equilibrium characteristics in each province. By using correlation analysis, principal component analysis and regional economic equilibrium index calculation, this paper studies the rationality of retail layout under the new retail background, and finally gives suggestions for later layout strategies.
\end{abstract}

Keywords: Economic society; retail layout; regional economies; development equilibrium.

\section{基于经济地理视角的供应链末端的布局分析}

\author{
崔彦博 ${ }^{1}$, 石磊 ${ }^{1}$, 黄起龙 ${ }^{1,2}$ \\ 1. 交通运输部科学研究院, 北京 中国; \\ 2. 北京交通大学经济管理学院, 北京 中国
}

摘 要: 本文选择主营电子消费品的小米公司所经营的线下门店的分布数据, 从区域经济角度 分析供应链末端的零售网点布局合理度。结合我国同期的省域经济社会发展现状, 利用官方 公布的GDP、人口、居民收入等统计资料, 开展多维度的数据分析, 对比省际的经济发展差异 和省内的均衡特征。全文利用相关性分析、主成分分析以及区域经济均衡度的指标计算, 研 究新零售背景下零售布局的合理性，并在后期针对门店的布局策略的不足给出建议。

关键词：经济社会；零售布局；区域经济；发展均衡度

\section{1. 前言}

当前, 我国城镇化的高度发展带动了区域的商业和物流变革, 作为供应链末端的零售业依托 互联网红利的线上线下融合发展呈现出新零售的特征。包括阿里、腾讯在内的互联网巨头也 更加注重开发线下资源, 凭借供应链管控、用户基础和数据共享, 营造消费场景引流 [1]。近 年来增长迅速的智能手机等终端的零售布局在很大程度上反映了区域的消费活力和供应链决 策水平。

在线上营销红利逐步裉去的背景下，依靠互联网起家的小米公司开始深耕线下零售，并依托 直营店 “小米之家” (以下简称米家) 和官方授权专卖店 (以下简称专卖店) 拓展线下推广、 销售、售后维修、技术支持等服务, 形成了以小米之家为代表的用户体验中心。按照企业自 身决策, 米家从起初以各大中心城市为阵地迅速扩散到国内二三线城市, 网点布局越织越密, 利用3年时间（到2018年）达到1000家 [2]。截至2017年底, 米家数量已达到115家, 专卖店数 量136家，共计251家。在体验性和既得性大大提高的同时，2017年小米手机国内销量增长 $32.6 \%$, 各门类产品线下出货量占比由 2016 年的 $32 \%$ 提高到 $42 \%[3]$ 。零售网点的迅猛发展需要 准确清晰的判断, 了解并发掘不同经济发展程度地区的市场需求, 实现产品供给的区域差异 化布局，发挥企业门店的最大效用。 
在商业的城市集聚上, 人口总量、腹地经济发展程度、当地购买力、交通便利度等都是吸引 零售布局的基本要素。人口总量、地方 GDP、人均收入等数据是经济地理中衡量区域市场体量 的常用指标。

经济首位度常用于衡量一个国家的首都或区域的中心城市中，核心城市在区域集群中的经济 贡献度, 洛伦兹曲线和由其推算得来基尼系数, 与衡量经济分布与人口分布差异程度的相对 发展率等, 组成了目前区域地理中衡量区域发展均衡程度的常用指标。在门店分布情况的分 析中，可以引入相关指标，用于评价区域内的门店分布的合理与否 [4]。

\section{2. 零售网点分布研究}

我国当前共有 34 个省级行政区划, 剔除行政管理制度和财政统计口径存在差异的港澳台外, 共有 31 个。由于工商管理制度差异, 小米门店在港澳台的总数只有两家。在大陆 31 个省、直 辖市、自治区中, 米家覆盖了 27 个, 其中贵州省有贵阳市 1 家米家店面升级中。在西藏自治区、 新疆维吾尔自治区、青海省、甘肃省目前暂无布局。本文选取以现有开业经营的 27 个省份为 样本进行分析。

小米现开设官方店面共 251 家, 其中米家 115 家, 小米专卖店 136 家。总体来看, 两种店面的按 省份划分，分布情况如下图1所示:

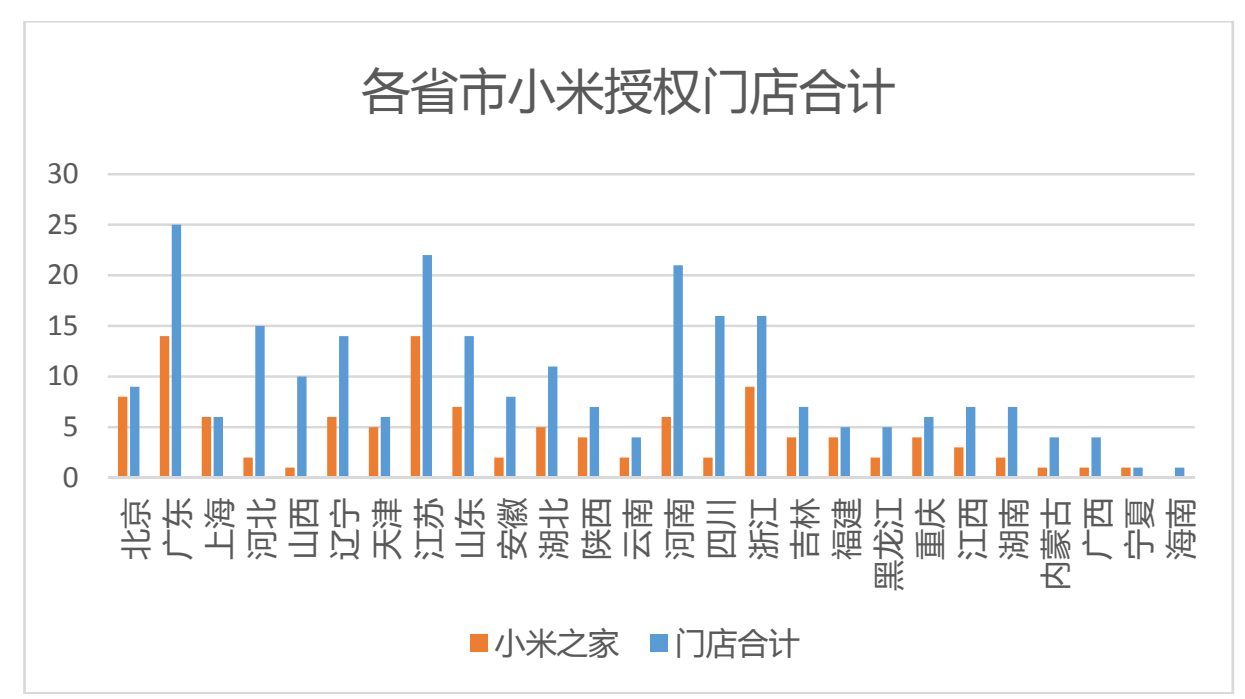

图1. 各省门店分布数量图

总体数量上, 广东、江苏两省占优, 米家数量均在 10 家以上, 专卖店超过 20 家, 分列第一、 第二。对应的两省的经济总量自2009年连续8年分列省级地区前两名。总量占优的人口大省河 南省门店数量居第三名, 门店数量超过 20 家, 与经济总量位居国内第四的浙江省并列第四。 山东、四川等人口和经济大省紧随其后。门店总量排在前六名的省份中, 除浙江外, 均为排 名前五的人口大省, 人口均超 8000 万人 [4]。五省人口总量占全国人口总量 $33.12 \%$, 拥有门 店数量占比 $39.2 \%$ 。从各省门店数量布局来看, 人口大省受到了较多青睐。而北京、上海、天 津等直辖市人口密度和商业集聚程度较高，起步最早，相比其他省份分布更加密集。

在细分类别中, 广东和江苏米家数量均超过 10 家, 浙江、北京、山东、河南、辽宁、上海等省 市均超过 5 家, 河南、四川、河北专卖店数量超过 10 家，三省 2017 年城镇化比率分别为 $48.5 \%$, $49.2 \%$, 和 $55.3 \%$ 。除宁夏和海南两个人口和经济总量较小的省份门店数量均为 1 家之外, 河北、 山西、安徽、四川、河南、湖南、内蒙古、广西等省份和自治区, 米家门店占比均低于 $40 \%$, 对应其中多数省份的城镇化率也低于 $50 \%$, 且均位于我国中西部。相对而言, 在中小城市仍以 官方授权的专卖店为主要形式, 米家主打一二线城市等经济基础较好地区。不同于专卖店, 米家作为官方授权的品牌形象店, 数量有待增加, 规模有待扩大。 


\section{1. 相关性分析}

为深入了解经济社会发展情况中具体单个指标与门店布局和类型选择的决策关系, 利用 $\mathrm{R}$ 作 图分别进行相关性分析。首先分析门店与人口类指标的相关程度, 以下列出部分相关性较强 的散点图作图2示例。

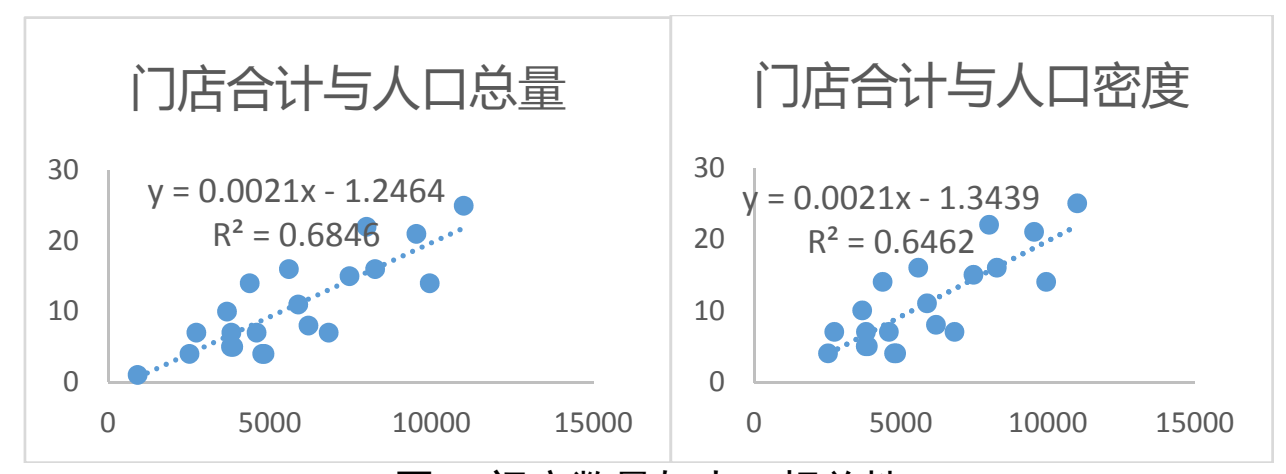

图2. 门店数量与人口相关性

由上组图及对应的测定系数 R 方可知, 门店合计的分布与人口总量和人口密度的相关系数均 超过 0.8 , 具有较强的相关性, 米家官方店与专卖店的门店合计数量与人口总量也呈较明显的 正相关趋势，反映了企业对于市场的供需关系的判断与决策相对合理。

对比上图, 并结合人口排名前十的省份的门店占比来比较, 可以发现人口数量与店面数成正 相关, 但并不是企业布局的决定性要素。北京市、上海市等经济发达的直辖市和浙江省、湖 北省、辽宁省、河北省等整体经济基础较好的省份在企业的供应链布局中同样受到重视。

查阅资料, 2016年, 我国分省市生产总值前五位 CR5分别为粤、苏、鲁、浙、豫, 五省相比全 国, 经济总量占比 $41.56 \%$, 人口占比 $31.23 \%$, 门店占全国总数近四成, 其中米家占比 $43.5 \%$, 与经济总量数据吻合度较高。CR 10 还包括川、鄂、冀、湘、闽 5 省, 10 省经济总量占比 $62.60 \%$, 人口数量占比 $54.12 \%$, 拥有门店比例为 $60.6 \%$, 其中米家占比为 $56.5 \%$, 低于 10 省经济总量所 占比例, 略高于人口总量比例, 可见当下米家的布局目的不仅在于销售商品, 更多是以店面 作为渠道下沉的产品宣传途径, 以塑造企业和产品形象, 扩大品牌影响力。因此, 在布局中 同时受商品购买和服务需求和潜在需求开发两方面。

将各省市 gdp 占比、人均 gdp 与其拥有的门店总数、米家数量分别进行线性分析, 门店总数 与省市的 gdp 总量相关性较强, 米家门店数与人均 gdp 的相关性较强。GDP、人均 GDP、人均 收入等指标与小米专卖店的数量相关度较弱。

从米家数量与省份 GDP、人均收入、人均 GDP 等指标来看, 广东、江苏两省的米家分布密度已 远高于其他省份, 相对处于饱和状态。河南、浙江、北京等省。整体偏离度不大, 但资源型 经济引导发展的内蒙古自治区人均经济指标长期以来占据优势, 在人均收入和人均 GDP 与米 家的相关性上偏离较大。四川、湖南、河北等经济总量大省的米家铺设密度有待增加, 购买 和服务等渠道潜力有较大进步空间。

\section{2. 主成分分析}

为更直观分析各指标对于门店布局的贡献程度, 采用 SPSS 软件进行主成分分析, 得到成分分 析矩阵和得分系数矩阵, 成分得分系数矩阵结果见下表 1 : 
表1.门店总数及米家成分得分系数矩阵

\begin{tabular}{ccc|c|c}
\hline & \multicolumn{2}{c}{ 门店总数成分 } & \multicolumn{2}{c}{ 米家成分 } \\
\cline { 2 - 5 } & 1 & 2 & 1 & 2 \\
\hline 人口 (2016) & -.001 & .533 & -.002 & .215 \\
\hline 人口密度 & .318 & -.103 & .371 & -.343 \\
\hline GDP 总量 & .149 & .490 & .268 & .423 \\
\hline 人均 GDP & .345 & -.041 & .392 & -.026 \\
\hline 人均收入 & .357 & -.071 & .435 & -.072 \\
\hline
\end{tabular}

从表 1 看出, 在以门店总数作为因变量的各省经济数据的主成分分析中, 人均收入和人口总量 两个因子对于门店数量的影响性最大。而在米家门店布局中, 人均 GDP 和 GDP 总量两个因子 决策参考性较强。这分别与米家和专卖店两者的功能定位基本相符, 当然, 要想进一步提高 产品形象, 增强销售与供应的运营服务能力, 部分人口总量较大的地区有待丰富和完善, 以 进一步发掘市场潜力, 扩大市场规模。

\section{3. 均衡度分析}

为了解小米门店在各省内部的区域分布差异, 引入经济首位度、相对发展率（NICH）、基于 洛伦兹曲线的不平衡指数 $\mathrm{S}$ 等三项指标, 与本省门店覆盖地市比率进行对比。其中 ( $\mathrm{n}$ 表示某 省拥有的地市个数, $\mathrm{Yi}$ 表示在排名前 $\mathrm{i}$ 个地市 $\mathrm{GDP}$ 或人口等占本身的累计百分比）：

$$
\begin{gathered}
\text { 省会经济首位度 }=\frac{\text { 本省省会经济总量 }}{\text { 本省整体经济总量 }} \\
N I C H=\frac{\max \left(G D P_{i}\right) \div p}{\sum_{i=1}^{n} G D P_{i}} \\
S=\frac{\sum_{i=1}^{n} Y_{i}-50(n+1)}{100 n-50(n+1)}
\end{gathered}
$$

按照上述公式（1）（2）（3）, 可得三项指标数据, 结合各省地市覆盖率, 由于上述经济首 位度、NICH、和 S 三个变量都与经济均衡度呈负相关, 且取值范围均存在差异, 需将门店覆 盖率转化为门店未覆盖率, 并统一三项指标的取值范围为 $0-1$, 做无量纲化处理。得出结果如 图4:

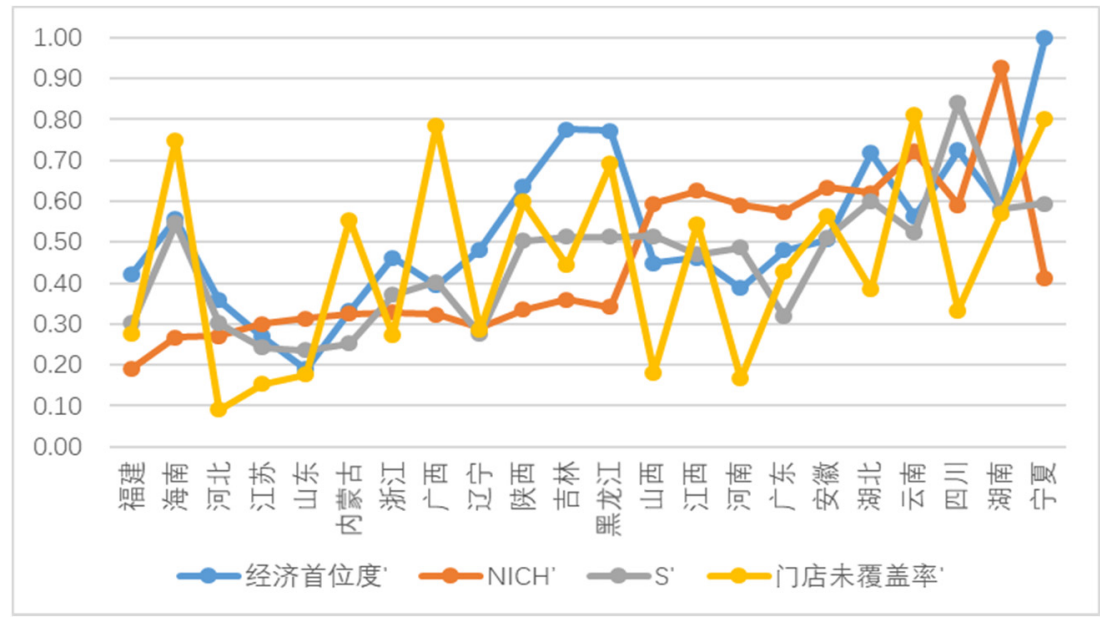

图3. 门店覆盖影响度分析 
从三项指标与门店未覆盖率的折线走势来看, 各省内零售门店的分布均衡程度, 基本与省会 经济首位度、相对发展率、以及不平衡指数相吻合, 相比之下, 省会城市的经济首位度和不 平衡指数与门店覆盖的相关程度更强。而河北、山西、河南等华北省份, 在门店覆盖上由于 客户基础相对扎实, 因而相对本省的主要均衡指标, 门店分布的情况更为均衡和完善。

\section{3. 结论与总结}

区域和城市发展的不平衡造就了供应链末端的零售的分布层级。截止统计时间，在所有供应 门店中, 小米之家的分布体现了较高的人口和经济集聚效应, 珠三角、长三角的江、浙、沪, 以及华北地区的京、鲁、豫三省市位列门店拥有量的榜单前七名, 占总数 $55.7 \%$ 。而在长江中 游和上游等人口密集市场活力充足的地区尚显滞后。

各省的门店总数分布差异以地区人口总量为导向, 但若是具体到每个城市, 则包括武汉、成 都、西安、重庆、长沙在内的人口大城尚显数量欠缺。而在人均经济总量和人口密度为导向 的小米之家的分布上, 福州、泉州等福建沿海及温州、台州等浙南城市的门店数有待增加。 此外, 对比各省内部的小米之家和授权专卖店的比例可知, 四川、河北、山西的小米之家比 例较低, 在本省门店占比均不超过 $15 \%$, 尤其是经济集聚度高、商业发达且市场广阔的成都仅 拥有 1 家小米之家, 这是后期的门店建设扩张中, 应当优先侧重的目的地。相比官方的授权店, 小米之家的规范化的管理运营能够进一步提高企业对于下游渠道的控制能力, 同时也应当利 用好授权专卖店，以更低的成本和更快的渠道下沉速度开发三四线城市。

\section{References}

[1]. Hu Zonal. The New Retail Logic of Retail Retailer Substance [J]. ECONOMIC\& TRADE UPDATE, 2017(29): 4.

[2]. Li Jing Yang. Research on Cost Leading Strategy of Xiao Company [D]. Master, Capital University of Economics and Business, Beijing, China. 2017. p5-p8.

[3]. Wang Dong. Analysis and Suggestion for Problems in Brand Communication of Xiao Mobile Phone [J]. Modern Business, 2018(05):1-2.

[4]. Cao Finding, Huang Zhen Fang, Wu Jiang. Analysis of Evolution and Causes of Temporal and Spatial Pattern of Regional Economic Differences in Jiangsu Province since 1990 [J]. Economic Geography, 2011, 31(06):895-902.

[5]. Information on: www.bycensus2016.gov.hk/tc/bc-articles.html. 